\title{
First isolation of Cryptococcus gattii molecular type VGII and Cryptococcus neoformans molecular type VNI from environmental sources in the city of Belém, Pará, Brazil
}

\author{
Solange do PSE Costa ${ }^{1 /{ }^{+}}$, Márcia dos S Lazéra ${ }^{2}$, Wallace RA Santos ${ }^{3}$, Bernardina P Morales ${ }^{2}$, \\ Cláudia CF Bezerra ${ }^{2}$, Marília M Nishikawa ${ }^{4}$, Gláucia G Barbosa ${ }^{2}$, Luciana Trilles², \\ José LM do Nascimento', Bodo Wanke²
}

${ }^{1}$ Instituto de Ciências Biológicas ${ }^{3}$ Instituto de Ciências da Saúde, Universidade Federal do Pará, Rua Augusto Corrêa 1, 66075-110 Belém, PA, Brasil ${ }^{2}$ Laboratório de Micologia, Instituto de Pesquisa Clínica Evandro Chagas-Fiocruz ${ }^{4}$ Instituto Nacional de Controle de Qualidade em Saúde-Fiocruz, Rio de Janeiro, RJ, Brasil

Cryptococcus neoformans and Cryptococcus gattii are important agents of meningoencephalitis in humans in the city of Belém. This clinical data suggests that the region may be a highly endemic area for the pathogenic Cryptococcus species within the state of Pará (PA), Northern Brazil. Preliminary analysis of 11 environmental samples from the city of Belém showed two positive locations, including a hollow of a kassod tree (Senna siamea) colonized simultaneously by C. gattii molecular type VGII and C. neoformans molecular type VNI, and a birdcage in a commercial aviary positive for C. neoformans, molecular type VNI. This is the first evidence of an environmental occurrence of molecular types VNI and VGII in PA.

Key words: Cryptococcus neoformans - Cryptococcus gattii - cryptococcosis - Belém - Pará

Cryptococcosis is a life-threatening systemic mycosis affecting healthy and immunocompromised hosts and is globally endemic. It is caused by two species of Cryptococcus: Cryptococcus neoformans (serotypes A, $\mathrm{D}$, and hybrid AD) and Cryptococcus gattii (serotypes $\mathrm{B}$ and $\mathrm{C}$ ), which differ genotypically, phenotypically, in epidemiology, as well as in their geographic distribution and ecologies (Perfect \& Casadevall 2002, Kwon Chung $\&$ Varma 2006). Mating type in this species is determined by a single genomic locus, with two idiomorphs termed MAT $\alpha$ and MAT a, making this species bipolar. MAT $\alpha$ strains are 30-40 times more prevalent than MAT a strains in most clinical and environmental sampling studies (Kwon-Chung \& Bennett 1992). Eight major molecular types have been identified within these two pathogenic species: C. neoformans is grouped into the molecular types VNI/AFLP1 (serotype A), VNII/ AFLP1A (serotype A), VNIII/AFLP2 (serotype AD) and VNIV/AFLP3 (serotype D); C. gattii is grouped into molecular types VGI/AFLP4, VGII/AFLP6, VGIII/ AFLP5 and VGIV/AFLP7 (serotypes B and C) (Meyer et al. 1999, Boekhout et al. 2001). These molecular classifications have been used for global epidemiological studies on cryptococcosis.

Financial support: FIOCRUZ/IPEC, CAPES, PQI (FIOCRUZ/UFPA/ NMT, CNPq 478990/2006-5)

+ Corresponding author: sol@ufpa.br

Received 3 August 2008

Accepted 13 May 2009
Cryptococcal infections are most often acquired through the inhalation of viable propagules from the environment. Although the lungs are the primary sites for the infection, dissemination leads to meningoencephalitis, which is the most frequently diagnosed clinical manifestation in humans. C. neoformans has a worldwide distribution, can be found in avian guano and tree hollows, and affects mainly immunocompromised hosts. C. gattii distribution prevails in tropical and subtropical regions and the organism is often associated with decomposing wood in the hollows of tropical trees. Several tree species have been found to be colonized by C. gattii, including Eucalyptus camaldulensis, in Australia and Mexico (Ellis \& Pfeiffer 1990, Licea et al. 1996), Terminalia cattapa, in Colombia (Callejas et al. 1998), and Syzygium jambolana, Cassia grandis, Senna multijuga, Ficus microcarpa, Moquilea tomentosa and Guettarda acreana, in Brasil (Lazera et al. 1996, 2000, 2005, Fortes et al. 2001).

C. gattii has the potential to cause life-threatening disease in immunocompetent hosts and is recognized as the main agent of endemic primary cryptococcosis in the Northeast Region of Brazil (Nishikawa et al. 2003). In addition, $C$. gattii has been the agent of one outbreak in captive psittacine birds in São Paulo, Brazil (Raso et al. 2004). C. gattii has attracted particular attention as a primary emerging pathogen on Vancouver Island, Canada, where an ongoing large-scale cryptococcosis outbreak in both humans and animals has been caused almost exclusively by $C$. gattii molecular type VGII (Kidd et al. 2004).

In 1999, Corrêa et al. reported a total of 19 cases of cryptococcosis in children in PA and nine of these cases 
were caused by $C$. gattii infections. A recent study in the same region showed that $C$. gattii is an endemic primary mycosis affecting HIV-negative hosts, including an unexpectedly high number of children, with most cases caused by molecular type VGII (Santos et al. 2008). Considering that some of these patients were from the Metropolitan area of Belém, the capital of PA, potential environmental sources for cryptococcal infection in this area were investigated in this current study.

The city of Belém $\left(01^{\circ} 27^{\prime} 20^{\prime \prime} \mathrm{S} 48^{\circ} 30^{\prime} 15^{\prime \prime} \mathrm{W}\right)$ has approximately $1.280,614$ inhabitants. Located at the mouth of the Amazon River, the city has a tropical and humid climate, with a consistently high relative humidity of about $85 \%$ (Prefeitura Municipal de Belém 2006).

For a preliminary analysis, sampling was performed in the quarters São Braz and Umarizal, both close to the Tropical Medicine Centre of the Federal University of PA, near the downtown region of the city. Four samples of caged psittacine dried bird excreta in three avian stores were collected. In addition, seven samples of decaying wood material were collected from each tree trunk hollow from trees found along the sidewalk. The trees included four Senna sp., one Senna siamea tree, one living tree that was not identified, and one trunk of a dead tree. Processing was conducted according to previously published protocols from Lazera et al. (1996).

Positive phenoloxidase colonies were isolated and tested for both thermotolerance at $37^{\circ} \mathrm{C}$ and cycloheximide sensitivity. The canavanine-glycine-bromothymol blue medium was used to determine if isolates were $C$. gattii (positive reaction and growth) or C. neoformans (negative reaction and no growth). Carbon and nitrogen compound assimilation was performed by the use of the Vitek 32-BioMerieux System (Vitek ICB, bioMeriux, Durham, USA) and the Crypto check kit (Iatron Laboratories, Tokyo, Japan) was used for serotyping of the isolates. After identification, the isolates were stored in Skim Milk medium (DIFCO) at $-20^{\circ} \mathrm{C}$.

Genomic DNA was extracted from isolates according to protocols from Ferrer et al. (2001). The mating type was determined using specific PCR primer pairs for mating type $\alpha$ and a, according to Chaturvedi et al. (2000). The $\alpha$-mating-type-specific primers were 5' -CTTCACTGCCATCTTCACCA-3' and 5' -GACACAAAGGGTCATGCCA-3', While the a-mating-typespecific primers were 5' -CGCCTTCACTGCTACCTTCT-3' and 5' -AACGCAAGAGTAAGTCGGGC-3'. Two type strains, ATCC 28957 (Mat $\alpha$ ) and ATCC 28958 (Mat a), were used as positive controls.

Restriction Fragment Length Polymorphism (RFLP) analysis using the URA5 gene was performed as described by Meyer et al. (2003) using the primers URA5 (5'ATGTCCTCCCAAGCCCTCGACTCCG3') and SJ01 (5'TTAAGACCTCTGAACACCGTACTC 3'). RFLP patterns were assigned visually by comparing them with the patterns obtained from the standard type strains (VNI-VNIV and VGI-VGIV).

One aviary store and one tree were positive for Cryptococcus. Five darkbrown colonies were obtained from a sample of bird droppings and all were identified as $C$. neoformans serotype A, MAT $\alpha$, molecular type VNI. Two dark brown colonies were obtained from decaying wood inside a hollow of a $S$. siamea tree (kassod tree); one colony was identified as C. neoformans serotype A, MAT $\alpha$, molecular type VNI and the other colony was identified as C. gattii serotype B, molecular type VGII. Mating type analysis is shown in Fig. 1 and the RFLP profiles are illustrated in Fig. 2.

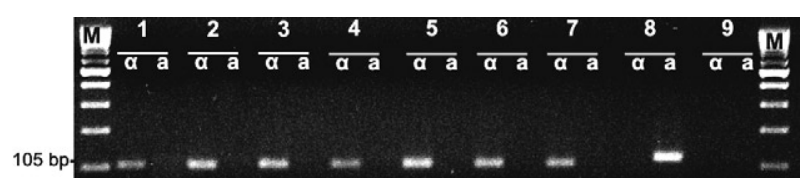

Fig. 1: PCR amplification of environmental isolates with primers MAT $\alpha 1$, MAT $\alpha 2$ and MAT a1, MAT a2. Lanes: M: molecular weight marker: 100 bp DNA ladder; 1: LMM 1082; 2: LMM 1083; 3: LMM 1084; 4: LMM 1088; 5: LMM 1089; 6: LMM 1090; 7: ATCC 28957; 8: ATCC 28958; 9: negative control.

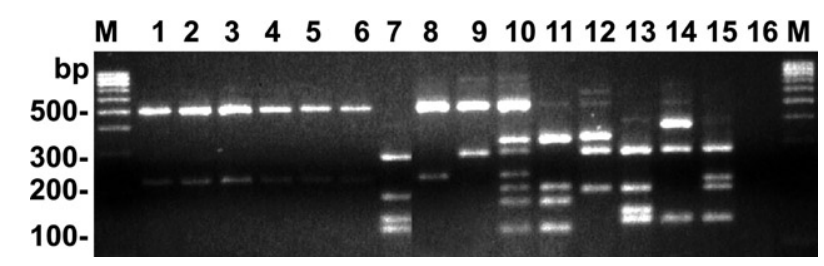

Fig. 2: molecular typing profiles generated via Restriction fragment length polymorphism analysis of URA5 from environmental isolates. Lanes: M: molecular weight marker: 100 bp DNA ladder; 1: LMM 1082; 2: LMM 1083; 3: LMM 1084; 4: LMM 1087; 5: LMM 1088; 6: LMM 1089; 7: LMM 1090; 8: LMM 794; 9: LMM 795; 10: LMM 796; 11: LMM 797; 12: LMM 798; 13: LMM 799; 14: LMM 800; 15: LMM 801; 16: negative control. All samples are molecular types VNI, except Lane 7, which is VGII. Lanes 8-15 are molecular type standard strains (VNI-VNIV and VGI-VGIV).

Few studies on the eco-epidemiology of $C$. neoformans and C. gattii have been performed in Northern Brazil. Fortes et al. (2001) demonstrated the occurrence of C. gattii in G. acreana in a wild area of the Amazon rainforest. In the present study, we report for the first time the isolation of $C$. neoformans and $C$. gattii from environmental sources in the city of Belém, PA. Trilles et al. (2008) analyzed the geographic distribution of $C$. neoformans and C. gattii molecular types from isolates within Brazil, and described VNI as the most common molecular type and VGII as the prevailing molecular type in immunocompetent hosts in the North and Northeast Regions of Brazil. Although a large number of isolates were analyzed $(n=443)$, none were from PA. Recently, Santos et al. (2008) analyzed the agents of 43 cases of cryptococcosis and found that VNI was the most common type in immunocompromised patients, while molecular type VGII was the major cause of endemic pri- 
mary mycosis in HIV-negative individuals, including an unexpectedly high number of children in PA.

Kidd et al. (2004) reported C. gattii molecular type VGII as the causative agent of the cryptococcosis outbreak on Vancouver Island (British Columbia, Canada). In addition, molecular studies of clinical and environmental isolates reported by Escandón et al. (2006) demonstrated the predominance of molecular type VGII within C. gattii isolates from Colombia. Moreover, the detection of molecular type VGII in a hollow of a tree in the city of Belém reinforces that this molecular type deserves increased attention in other parts of the Brazilian Amazonia as well as in other South American countries.

\section{ACKNOWLEDGEMENTS}

To Antonio Sérgio Lima (MPEG), for in the identification of botanic specimen, and to Roseane Norat, for her technical assistance.

\section{REFERENCES}

Boekhout T, Theelen B, Diaz M, Fell JW, Hop WCJ, Abeln ECA, Dromer F, Meyer W 2001. Hybrids genotypes in the pathogenic yeast Cryptococcus neoformans. Microbiology 147: 891-907.

Callejas A, Ordoñez N, Rodrigues MC, Castañeda E 1998. First isolation of Cryptococcus neoformans var. gattii serotype C from the environment in Colombia. Med Mycol 36: 341-344.

Chaturvedi S, Rodeghier B, Fan J, McClelland CM, Wickes BL, Chaturvedi V 2000. Direct PCR of Cryptococcus neoformans MAT alfa and MAT a pheromones to determine mating type, ploidy and variety: a tool for epidemiological and molecular pathogenesis studies. J Clin Microbiol 38: 2007-2009.

Corrêa MPSC, Oliveira EC, Duarte RRBS, Pardal PPO, Oliveira FM, Severo LC 1999. Criptococose em crianças no estado do Pará, Brasil. Rev Soc Bras Med Trop 32: 505-508.

Ellis DH, Pfeiffer TJ 1990. Natural habitat of Cryptococcus neoformans var. gattii. J Clin Microbiol 28: 1642-1644.

Escandón P, Sánchez A, Martínez M, Meyer W, Castañeda E 2006. Molecular epidemiology of clinical and environmental isolates of Cryptococcus neoformans species complex reveals as high genetic diversity and presence of the molecular type VGII mating type a in Colombia. FEMS Yeast Res 6: 625-635.

Ferrer C, Colom F, Frase S, Mulet E, Abad JL, Alio, JL 2001. Detection and identification of fungal pathogens by PCR and by ITS2 and 5.8S ribosomal DNA typing in ocular infections. $J$ Clin Microbiol 39: 2873-2879.

Fortes ST, Lazéra MS, Nishikawa MM, Macedo RCL, Wanke B 2001. First isolation of Cryptococcus neoformans var. gattii from a native jungle tree in the Brazilian Amazon rainforest. Mycoses 44: 137-140.

Kidd SE, Hagen F, Tscharke RL, Huynh M, Barlett KH, Fyfe M, McDougall L, Boekhout T, Kwon-Chung KJ, Meyer W 2004. A rare genotype of Cryptococcus gattii caused the cryptococcosis outbreak on Vancouver Island (British Columbia, Canada). Proc Natl Acad Sci USA 101: 17258-17263.
Kwon-Chung KJ, Bennett JE 1992. Cryptococcosis. In KJ KwonChung, JE Bennet (eds.), Medical mycology, Lea \& Febiger, Philadelphia, p. 397-446.

Kwon-Chung KJ, Varma SA 2006. Do major species concepts support one, two or more species within Cryptococcus neoformans? FEMS Yeast Res 6: 574-587.

Lazéra MS, Cavalcanti MAS, Londero AT, Trilles L, Nishikawa MM, Wanke B 2000. Possible primary ecological niche of Cryptococcus neoformans. Med Mycol 38: 379-383.

Lazéra MS, Gutierrez-Galhardo MC, Cavalcanti MAS, Wanke B 2005. Criptococose. In JR Coura (ed.), Dinâmica das doenças infecciosas e parasitárias, Vol. II, Guanabara Koogan, Rio de Janeiro, p. 1223-1235.

Lazéra MS, Pires FDA, Camillo-Coura L, Nishikawa MM, Bezera CCF, Trilles L, Wanke B 1996. Natural habitat of Cryptococcus neoformans var. neoformans in decaying wood forming hollows in living trees. J Med Vet Mycol 34: 127-131.

Licea BA, Garza DG, Zúñiga MT 1996. Aislamento de Cryptococcus neoformans var. gattii de Eucalyptus tereticornis. Rev Iberoam Micol 13: 27-28.

Meyer W, Castañeda A, Jackson S, Huynh M, Castañeda E 2003. Molecular typing of Iberoamerican Cryptococcus neoformans isolates. Emerg Infect Dis 9: 189-195.

Meyer W, Marszewske K, Amirnostofian M, Igreja RP, Hardtke C, Methling K, Viviani MA, Clindamporn A, Sucroogreung S, John MA, Ellis D, Sorrell TC 1999. Molecular typing of global isolates of Cryptococcus neoformans by polymerase chain reaction fingerprinting and randomly amplified polymorphic DNA - a pilot study to standertize tecnhiques on wich to base a detailed epidemiological survey. Electrophoresis 20: 1790-1799.

Nishikawa MM, Lazéra MS, Barbosa GG, Trilles L, Balassiano BR, Macedo RCL, Bezerra CCF, Pérez MA, Cardarelli P, Wanke B 2003. Serotyping of 467 Cryptococcus neoformans isolates from clinical and environmental sources in Brazil: analysis of host and regional patterns. J Clin Microbiol 41: 73-74.

Perfect JR, Casadevall A 2002 . Cryptococcosis. Infect Dis Clin North Am 16: 837-874.

Prefeitura Municipal de Belém 2006. Indicadores da Cidade de Belém, SEGEP, Departamento de Pesquisa e Informação, Belém, p. 1-60.

Raso TF, Werther K, Miranda T, Mendes-Giannini MJS 2004. Cryptococcosis outbreak in psittacine birds in Brazil. Med Mycol 42: $355-362$.

Santos WRA, Meyer W, Wanke B, Costa SPSE, Trilles L, Nascimento JLM, Medeiros R, Morales BP, Bezerra CCF, Macêdo RCL, Ferreira SO, Barbosa GG, Perez MA, Nishikawa MM, Lazéra MS 2008. Primary endemic cryptococcosis gattii by molecular type VGII in the state of Pará, Brazil. Mem Inst Oswaldo Cruz 103: $813-818$

Trilles L, Lazera M, Wanke B, Oliveira RV, Barbosa GG, Nishikawa MM, Morales BP, Meyer W 2008. Regional pattern of the molecular types of Cryptococcus neoformans and Cryptococcus gattii in Brazil. Mem Inst Oswaldo Cruz 103: 455-462. 